\title{
Pulmonary hypertension in low- and middle-income countries with focus on sub-Saharan Africa
}

\author{
Anastase Dzudie ${ }^{1,2,3}$, Bonaventure Suiru Dzekem ${ }^{3}$, Dike B. Ojji ${ }^{4}$, Andre Pascal Kengne ${ }^{5}$, \\ Ana Olga Mocumbi ${ }^{6,7}$, Karen Sliwa ${ }^{8}$, Friedrich Thienemann ${ }^{8,9,10}$
}

${ }^{1}$ Departments of Internal Medicine and Physiology, Faculty of Medicine, University of Yaoundé, Yaoundé, Cameroon; ${ }^{2}$ Departments of Internal Medicine and Cardiology, Douala General Hospital, Douala, Cameroon; ${ }^{3}$ Clinical Research Education, Networking and Consultancy, Douala, Cameroon; ${ }^{4}$ Department of Medicine, Faculty of Clinical Sciences, University of Abuja, and University of Abuja Teaching Hospital, Gwagwalada, Abuja, Nigeria; ${ }^{5}$ Non Communicable Diseases Research Unit, South African Medical Research Council, Cape Town, South Africa; ${ }^{6}$ Instituto Nacional de Saúde, Maputo, Mozambique; ${ }^{7}$ Universidade Eduardo Mondlane, Maputo, Mozambique; ${ }^{8}$ Hatter Institute for Cardiovascular Research in Africa, Department of Medicine, Faculty of Health Sciences, University of Cape Town, Cape Town, South Africa; ${ }^{9}$ Department of Internal Medicine, University Hospital Zurich, University of Zurich, Zurich, Switzerland; ${ }^{10}$ Wellcome Centre for Infectious Diseases Research in Africa, Institute of Infectious Disease and Molecular Medicine, Faculty of Health Sciences, University of Cape Town, Cape Town, South Africa

Contributions: (I) Conception and design: A Dzudie, BS Dzekem, F Thienemann; (II) Administrative support: None; (III) Provision of study materials or patients: None; (IV) Collection and assembly of data: None; (V) Data analysis and interpretation: A Dzudie, DB Ojji, K Sliwa, AP Kengne, AO Mocumbi, F Thienemann; (VI) Manuscript writing: All authors; (VII) Final approval of manuscript: All authors.

Correspondence to: Anastase Dzudie. Douala General Hospital and Clinical Research Education, Networking and Consultancy, P.O. Box 3480, Douala, Cameroon. Email: aitdzudie@yahoo.com.

\begin{abstract}
Pulmonary hypertension $(\mathrm{PH})$ is a devastating, progressive disease with increasingly debilitating symptoms and usually shortened overall life expectancy. This article reviews the global epidemiology of PH with focus on low- and middle-income countries (LMICs) and sub-Sahara African in particular. Although left ventricular heart disease is the most common cause globally, the main contributing risk factors in LMICs are chronic infectious diseases especially human immunodeficiency virus (HIV) and schistosomiasis. Other important risk factors of $\mathrm{PH}$ are rheumatic heart disease, untreated congenital heart disease (CHD), and sickle cell disease. Despite existing epidemiological data of $\mathrm{PH}$ risk factors suggesting a high prevalence in sub-Saharan Africa (SSA), the available literature is limited. International registries in LMICs like the pan African pulmonary hypertension cohort (PAPUCO) study are essential to provide information about the causes, treatment, outcome, and the natural course of $\mathrm{PH}$ in Africa and other parts of the world. In addition, there is a need to track diagnostic and management practices in order to develop suitable algorithms to diagnose $\mathrm{PH}$ in LMICs.
\end{abstract}

Keywords: Pulmonary hypertension (PH); epidemiology; Africa; low- and middle-income countries (LMICs)

Submitted May 23, 2019. Accepted for publication Jul 18, 2019.

doi: $10.21037 / \mathrm{cdt} .2019 .07 .06$

View this article at: http://dx.doi.org/10.21037/cdt.2019.07.06

\section{Introduction}

Pulmonary hypertension ( $\mathrm{PH})$ is a devastating, progressive disease with increasingly debilitating symptoms and usually shortened overall life expectancy due to narrowing of the pulmonary vasculature and consecutive right heart failure (RHF). $\mathrm{PH}$ is defined by an increase in mean pulmonary arterial pressure $(\mathrm{mPAP})>25 \mathrm{mmHg}$ at rest assessed by right heart catheterization $(1,2)$ or by echocardiography with a right ventricular systolic pressure (RVSP) $>35 \mathrm{mmHg}$, absence of pulmonary stenosis and acute RHF, and usually accompanied by shortness of breath, fatigue, peripheral edema and other cardiovascular symptoms (3). PH can be 


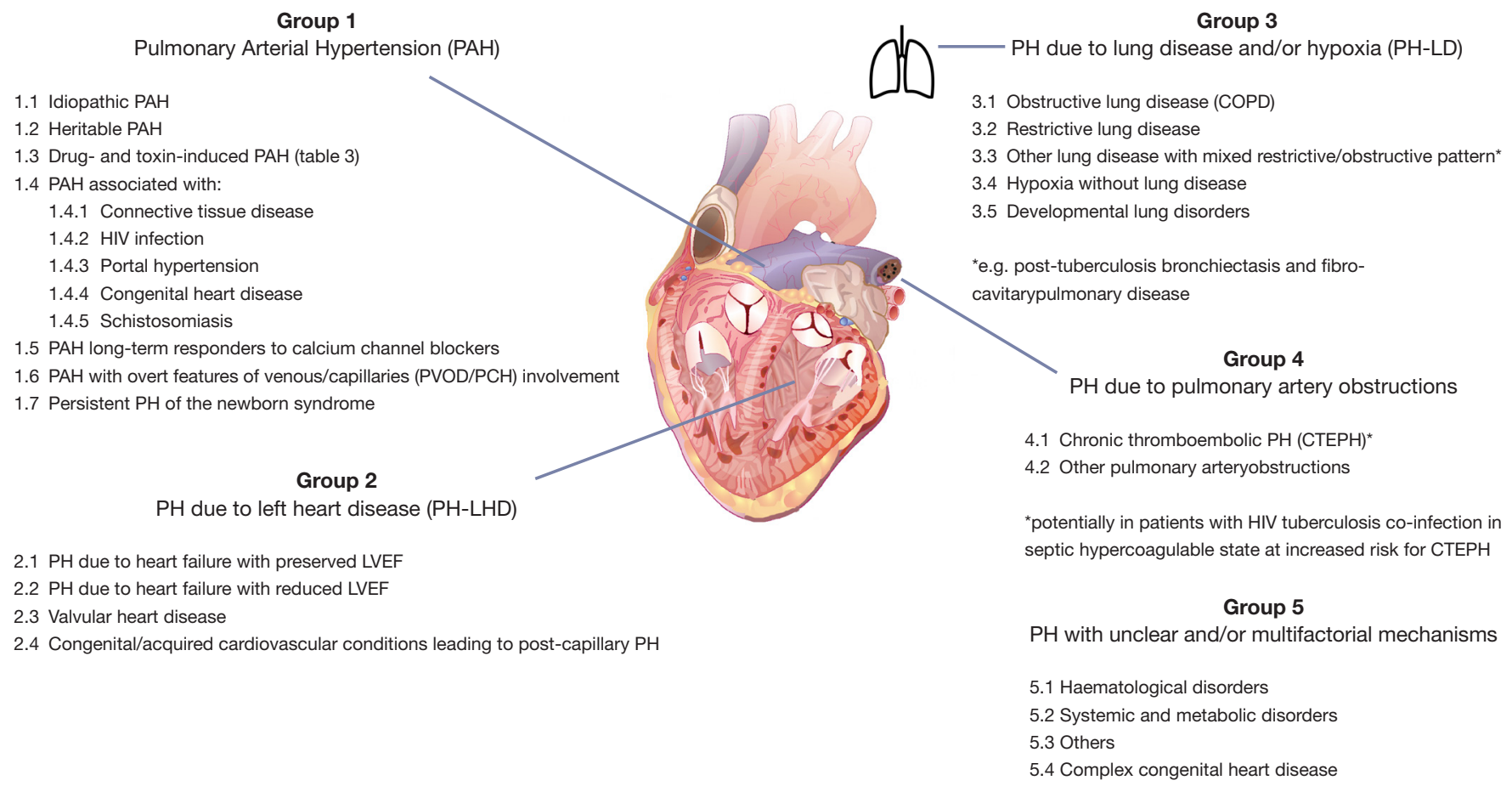

Figure 1 The figure illustrates the updated clinical classification of $\mathrm{PH}$ with emphasis on risk factors and co-morbidities prevalent in LMICs according to the $6^{\text {th }}$ WSPH task force published by Simonneau et al. (4). PH, pulmonary hypertension; LMICs, low- and middle-income countries; WSPH, World Symposium on Pulmonary Hypertension; LVEF, left ventricular ejection fraction; HIV, human immunodeficiency virus; COPD, chronic obstructive pulmonary disease.

caused by a multitude of conditions and co-morbidities highly prevalent in low- and middle-income countries (LMICs) and may complicate the majority of respiratory and cardiovascular diseases leading to excess morbidity and mortality in these multi-morbid patients.

Figure 1 illustrates the updated clinical classification of $\mathrm{PH}$ with emphasis on risk factors and co-morbidities prevalent in LMICs according to the $6^{\text {th }}$ World Symposium on Pulmonary Hypertension (WSPH) task force published by Simonneau et al. (4). Group 1 (pulmonary arterial hypertension, $\mathrm{PAH}$ ) includes idiopathic, heritable, and drug-induced $\mathrm{PAH}$ and is associated with conditions such as human immunodeficiency virus (HIV), schistosomiasis, and congenital heart disease (CHD). Group 2 includes $\mathrm{PH}$ due to left heart disease (PH-LHD) related to systolic dysfunction, diastolic dysfunction, valvular disease, or a combination of these conditions. $\mathrm{PH}$ resulting from lung diseases and hypoxemia, or both, comprises Group $3 \mathrm{PH}-$ $\mathrm{LD}$ and is associated with chronic obstructive pulmonary disease (COPD), interstitial lung disease, pulmonary diseases with a mixed restrictive and obstructive pattern. Post tuberculosis (TB) bronchiectasis and fibrotic-cavitary pulmonary disease is another major risk factor for the development of Group 3 PH. Chronic thromboembolic pulmonary hypertension (CTEPH) corresponds to Group 4, and Group 5 includes a heterogeneous group of disorders that may cause $\mathrm{PH}$ by unclear or multiple mechanisms, or both $(1,2,4,5)$.

In the last decades, significant progresses in the diagnosis and management of $\mathrm{PH}$ have gradually moved this condition from an orphan disease to major global health problem (6). It is estimated that about $80 \%$ of the global burden of the disease is in LMICs where $\mathrm{PH}$ is known to be highly associated with CHD, rheumatic heart disease, schistosomiasis and HIV (6,7). Despite these risk factors for $\mathrm{PH}$, left heart disease (LHD) still remains the most common etiology for $\mathrm{PH}$ in both LMICs and high-income countries (HICs) (8-10). Contrary to what is observed in HICs where $\mathrm{PH}$ is predominant in the elderly above the ages of 65 years, it is very common in younger individuals 


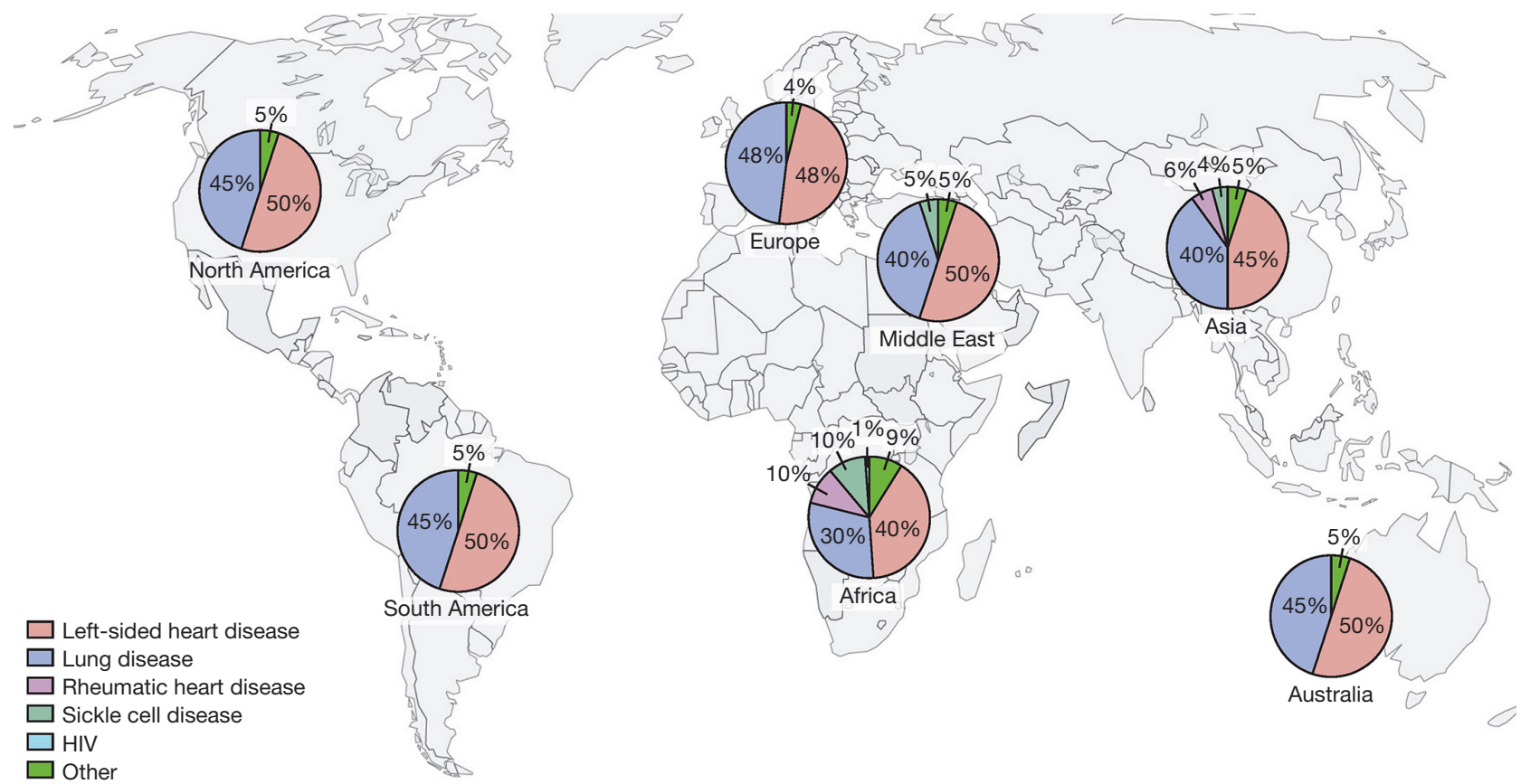

Figure 2 Estimated global distribution of most forms of PH. LHDs are the most common underlying cause of PH on all continents, followed by lung disease. Not shown in this figure is schistosomiasis associated PH which is most commonly found in South America, while data from other regions is lacking. Adapted from Hoeper et al. (7). PH, pulmonary hypertension; LHD, left heart disease.

in LMICs (7).

LMICs are known to have limited resources for the diagnosis and treatment of several diseases including PH. $\mathrm{PH}$ has debilitating symptoms and if left untreated, it has poor survival and reduced life expectancy $(11,12)$. Another well-known factor that has accounted for high mortality rates in sub-Saharan Africa (SSA) is the fact that patients in these settings usually present to the hospital at late stages of the disease (WHO functional class III and IV) $(3,8,13)$. This is mainly due to two reasons: (I) accessibility to health care, and (II) non-specific nature of $\mathrm{PH}$ symptoms such as shortness of breath and fatigue. In addition to the above, there is lack of adequate diagnostic tools at primary care, with most cases in SSA and other LMICs are usually misdiagnosed as heart failure, other cardio-respiratory conditions, or even TB $(12,14)$.

Recent advances have been made in the development of effective treatments, especially for PAH and CTEPH $(15,16)$. Vasodilators, endothelin receptor antagonists, phosphodiesterase (PDE) inhibitors (e.g., sildenafil) and high-dose calcium channel blockers (e.g., amlodipine) are the most commonly prescribed drug, with the latter two also available in SSA and other LIMC (17). CTEPH is a potentially curable disease when treated with pulmonary thromboendarterectomy (PTE).

Nonetheless of all advances in the management of $\mathrm{PH}$, there is still limited data on the epidemiology of $\mathrm{PH}$ in LMICs. The pan African pulmonary hypertension cohort (PAPUCO) study provides the most comprehensive data on the prevalence, etiologies, classification, morbidity and mortality of $\mathrm{PH}$ on the African continent $(3,17)$.

\section{Epidemiology of PH}

The exact global burden of $\mathrm{PH}$ remains unknows, and most likely largely underestimated due to the abovementioned circumstances in LMICs. It is estimated that about $80 \%$ of patients with PH live in LMICs and disproportionately affecting younger people at an age $<65$ years (7). Overall, LHD still remains the dominant risk factor for PH (PH-LHD), followed by chronic lung disease and hypoxia (PH-LD), while $\mathrm{PAH}$ remains rare even in high HIV prevalent settings in SSA (Figure 2), where also untreated streptococcal infections leading to 


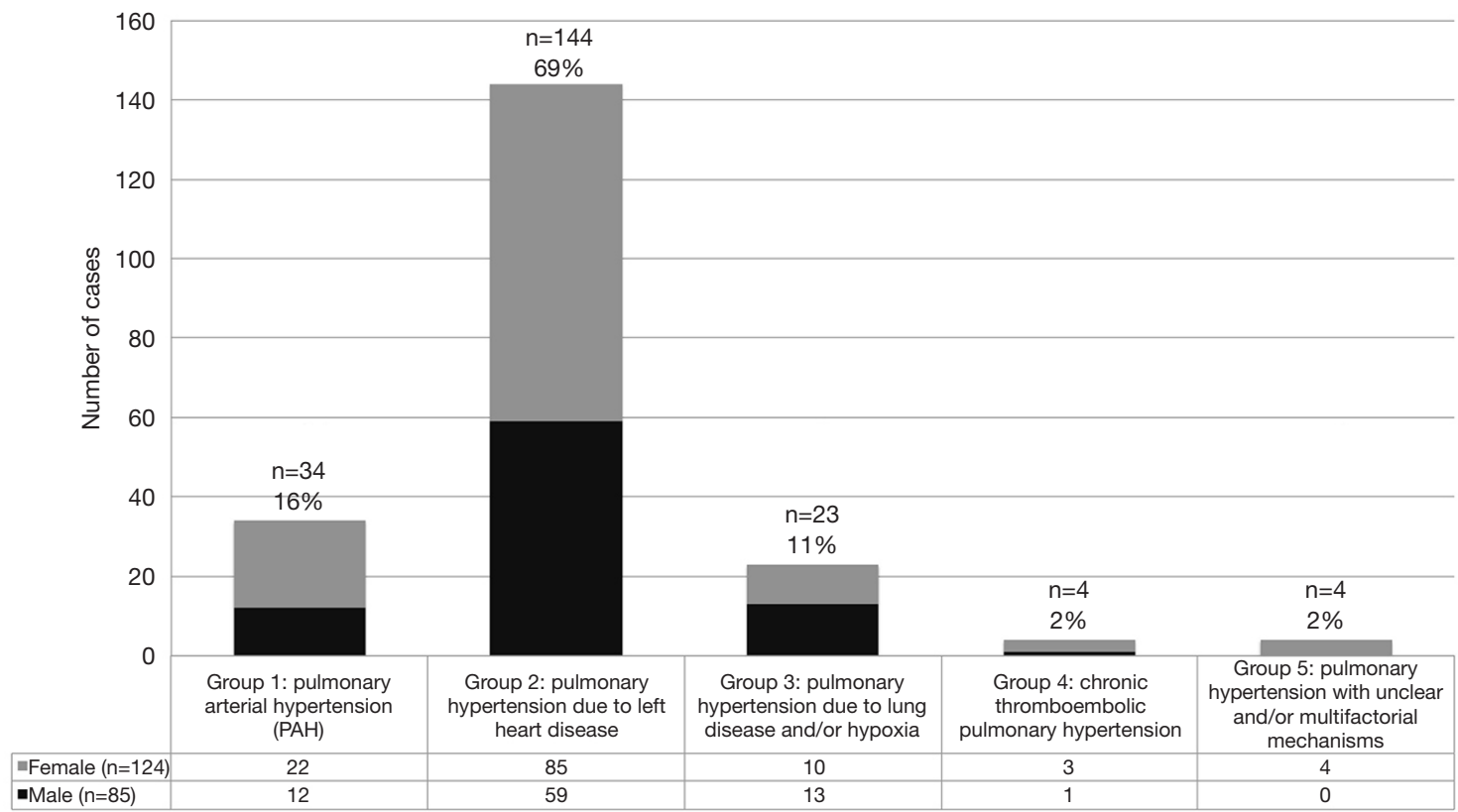

Figure 3 Subgroup classification of adult cases of the PAPUCO study according to contemporary WHO criteria revealed that $16 \%$ of patients as Group 1 (PAH), 69\% as Group 2 (PH-LHD), 11\% as Group 3 (PH-LD ), 2\% as Group 4 (CTEPH), and 2\% as Group 5 (PH with unclear/multifactorial mechanism). PAPUCO, pan African pulmonary hypertension cohort; $\mathrm{PH}$, pulmonary hypertension; PAH, pulmonary arterial hypertension; PH-LHD, PH due to left heart disease; PH-LD, PH due to lung disease and/or hypoxia; CTEPH, chronic thromboembolic pulmonary hypertension.

rheumatic fever rheumatic heart disease and sickle cell disease are endemic $(3,6,7,18)$. As of 2015 , it was estimated that up to 50-70 million individuals were affected by $\mathrm{PH}$ globally, which is expected to rise as global population and life expectancy increases $(7,19)$. About 30 million individuals are estimated to have heart failure associated $\mathrm{PH}, 25$ million estimated to have COPD associated $\mathrm{PH}$, 150,000 individuals estimated to have HIV-associated PH (HIV-PH), 3.75 million individuals estimated to suffer rheumatic heart disease associated $\mathrm{PH}$, and 2 million individuals estimated to have sickle cell disease associated PH (7).

Mortality of $\mathrm{PH}$ is high in both LMICs and HICs (20-24). A 5-year mortality rate of $26 \%$ was recorded in a Swiss cohort of PAH, CTEPH and PH-LD patients (11). Similar mortality rates have been recorded in SSA in a short observational period of only 6 months $(3,8)$. The PAPUCO study described the causes, treatment and outcome of $\mathrm{PH}$ in Africa in both adult and pediatric populations (3). According to this continent wide study, $69 \%$ of $\mathrm{PH}-\mathrm{LHD}, 16 \%$ due to $\mathrm{PAH}, 11 \%$ of $\mathrm{PH}-\mathrm{LD}$,
2\% due to CTEPH, and 2\% due to multifactorial/unclear mechanism (Figure 3).

In PAPUCO, we found a high 6-month mortality of $21 \%$ in adults associated with functional limitations at time of presentation. To our knowledge, PAPUCO remains the only study that has classified $\mathrm{PH}$ according to the current guidelines. In a recent review on PH in Africa, findings showed that the prevalence of $\mathrm{PH}$ varies widely across different population: $9.8 \%$ in patients presenting with cardio-respiratory complaints, $10 \%$ in HIV-infected patients, $32.9 \%$ in patients with heart failure, $23.2 \%$ in patients on hemodialysis, $12.9 \%$ in patients with RHD, $37 \%$ to $53 \%$ in patients with sickle cell disease $(9,22,25,26)$.

The high prevalence of PH-LHD in LMICs is expected due to a higher prevalence of uncontrolled hypertension which is also a principal cause of heart failure according to the sub-Saharan acute heart failure (THESUS-HF) study, a study conducted in nine African countries (27). Lung disease and hypoxia is known to be the second leading cause of PH after LHD. Studies from SSA suggest a relationship 
between indoor exposure to smoke from burning biomass and $\mathrm{PH}$, but the actual risk has not been fully explored $(3,8)$. A study from Egypt reported a prevalence of $63 \%$ among patients with COPD (28). Another study in Libya showed a prevalence of $8 \%$ among patients with pulmonary disease (29). The high prevalence of COPD across all age groups may be linked to occupation risk such as mining, direct and passive smoking, urban pollution, and indoor pollution from domestic fires for cooking and heating, as well as to endemic levels of TB leading to post-TB bronchiectasis and fibro-cavitary pulmonary disease with COPD type pattern (TB obstructive pulmonary disease, TOPD) (3). Ahmed et al. published a case series of 14 Sudanese patients with $\mathrm{PH}$ after successful completion of treatment for TB. The group reported further different severity and grades of $\mathrm{PH}$ with a median time from completion of treatment to TB to diagnosis of $\mathrm{PH}$ of nine years, suggesting an underestimated burden of persistent morbidity in TB globally in patients defined as "cured" by microbiologic means (30).

A South African study identified $\mathrm{PH}$ as one of the commonest causes of death accounting for $31 \%$ of total cardiovascular deaths (31). A study in Cameroon reported 6 -month mortality rates of $28 \%$ (8). The reasons for high mortality rates in LMICs are lack of access to health care, infrastructure and equipment to diagnose $\mathrm{PH}$ within the health care system, and availability of specific treatment for PH. In Mexico a study involving patients with CTEPH reported that only one patient out of 50 underwent pulmonary endarterectomy despite many patients being eligible. Reasons identified were lack of insurance coverage for patients eligible for surgery and lack of infrastructure for post-operative care after the procedure (32).

People living with HIV have an increased risk of developing PH. With HIV being more prevalent in LMICs and endemic in SSA it is expected that there will be a higher burden of $\mathrm{PAH}$ in this region. To date, no systematic studies have been carried out to report the incidence of PH among HIV patients in SSA. On a global scale, the prevalence of $\mathrm{PH}$ in $\mathrm{HIV}$-infected individuals varies between $0.5 \%$ and $5.0 \%$ with HIV being recognized as an independent risk factor for the development of $\mathrm{PH}$. The prevalence of HIV-PH in developed countries in the era of combined antiretroviral therapy (cART) is $0.5 \%$, while $5.5 \%$ of patients with no symptoms of $\mathrm{PH}$ may be at risk for $\mathrm{PH} ; 1,000$-fold higher than in the general population. Studies conducted in Africa found evidence of $\mathrm{PH}$ by echocardiographic measurements in $0.6-5 \%$ of HIV patients in Nigeria, Burkina Faso, and Zimbabwe. Estimated survival rates in developed countries in the pre-cART era were about $70 \%$ at 1 year and $50 \%$ at 3 years compared with about $90 \%$ at 1 year and $70 \%$ at 3 years after the advent of cART. Even though these data seem convincing a direct benefit of cART on the incidence and survival of HIV-PH could not be demonstrated. Combination antiretroviral therapy alone without specific treatment for $\mathrm{PH}$ does not result in an improved cardiac function. Also, no association between HIV-PH and CD4 count, viral load, or stage of disease could be identified. Thus, the prevalence of $\mathrm{PH}$ among HIV patients in the African context varies widely. Studies also report a slight female predominance (33). It would be relevant to investigate in a large cohort study the true incidence and factors that affect the occurrence of HIV-PH.

Schistosomiasis has been identified to be one of the major causes of $\mathrm{PH}$ as a result of host immune response to the parasite antigen. Worldwide, 200 million people are infected by Schistosomiasis, with majority of these living in LMICs especially in Africa, parts of Asia and South America. About 1\% of people with schistosomiasis develop PH $(34,35)$. Sickle cell disease is another identified risk factor that has been associated with PH. In Nigeria, a case-control study among patients with sickle cell disease revealed a prevalence of $22.9 \%$ in patients with hemoglobin SS as compared to $2.3 \%$ in patients with hemoglobin AA (36). In another echocardiography study, $\mathrm{PH}$ was detected in $23.9 \%$ of adults with sickle cell disease (37), with reported higher mortality in these group of patients (38).

\section{Pathogenesis of PH}

The pathogenesis of $\mathrm{PH}$ is different for every clinical WHO group and the underlying risk factors, diseases and co-morbidities contribute to pathophysiological changes in the heart, lungs and pulmonary arteries. $\mathrm{PH}$ presents as a clinical syndrome characterized by shortness of breath and loss of exercise capacity that is related to increased PAP and pulmonary vascular resistance (PVR), with vasoconstriction, proliferation, thrombosis, and re-modelling of the pulmonary vessels (4). Vasoconstriction occurs in early disease, followed by micro-thrombotic embolism. Remodelling of the small and middle size pulmonary arteries is the critical factor leading to disease progression with 
increasing morbidity and mortality.

\section{Management PH in LMICs}

A number of guidelines exist for the diagnosis and treatment of $\mathrm{PH}$, but the joined European Society of Cardiology (ESC) and the European Respiratory Society (ERS) guidelines for the diagnosis and treatment of $\mathrm{PH}$ are the most comprehensively used, regularly updated and widely recognized in $\mathrm{PH}$. The 2015 guidelines provide some changes from the 2009 guidelines, including but not limited to simplified content structure, new parameters for the hemodynamic definition of post-capillary $\mathrm{PH}$, the inclusion PVR in the hemodynamic definition of PAH, and updated diagnostic and treatment algorithms (1). With limitations in clinical and hemodynamic characterization of $\mathrm{PH}$ based on a resting value of mean pulmonary artery pressure alone, recent suggestions have been made to include a PVR $\geq 3$ Wood Units in the definition of all forms of pre-capillary $\mathrm{PH}$ and a cut-off point of $\mathrm{mPAP} \geq 20 \mathrm{mmHg}(1,4)$.

According to ESC/ERS guidelines, the standard procedures in a patient with suspected $\mathrm{PH}$ are complex investigations inclusive, but not limited to doppler echocardiography (doppler echo), pulmonary angiography, right heart and left heart catheterization, high-resolution computed tomography, lung function testing, and ventilation/perfusion scan (V/Q scan) $(1,2)$. The above diagnostic techniques require high skilled operational personnel, continuous technical maintenance or even radionucleotides, mostly not readily available in resource limited settings, or only available in large urban centers such as university hospitals.

Doppler echo has been shown to be highly specific and sensitive in the detection of $\mathrm{PH}$, if in the hands of a welltrained cardiologist or technician (39). In the context of the previously described limitations in LMICs and with PH-LHD being the most frequent form of $\mathrm{PH}$, our group recently provided a simplified diagnostic algorithm (Figure 4) for the diagnosis of PH-LHD in resource-limited settings (40). This four-step diagnostic approach includes in step (I) a clinical evaluation to detect predisposing conditions for PH-LHD such as hypertension, and signs including pitting edema, raised jugular venous pressure, nail clubbing; step (II) assessment with chest X-ray and electrocardiogram to uncover the presence of PH-LHD such as cardiomegaly with enlarged right atrium and pulmonary arteries, prominent pulmonary outflow tract, and pruning of peripheral pulmonary vessels on chest $\mathrm{X}$-ray, and sinus tachycardia with right-axis deviation, right atrial enlargement, ventricular hypertrophy and strain, and broadening of the QRS complex on electrocardiogram; step (III) confirmation of the presence of PH-LHD using doppler echo, and step (IV) investigation of differential etiologies and classification of the clinical WHO group of $\mathrm{PH}$.

Despite advances in treatment of various forms of $\mathrm{PH}$, specific PH drugs are still largely unavailable in LMICs. Specific drugs for $\mathrm{PH}$ such as vasodilators, endothelin receptor antagonists, phosphodiesterase PDE inhibitors (e.g., sildenafil) and high-dose calcium channel blockers (e.g., amlodipine) are the most common prescribed drug, with the latter two at least available in some LIMC. In most regions of the world, drugs used to manage all forms of $\mathrm{PH}$ remain those for the management of heart failure including diuretics, calcium channel blockers, angiotensin-convertingenzyme (ACE) inhibitor, angiotensin II receptor blockers (ARB), beta blockers, digitalis, and anti-coagulants $(3,41)$.

\section{Conclusions}

$\mathrm{PH}$ is a common clinical syndrome in SSA and other LMICs and many of the identified risk factors for $\mathrm{PH}$ are hyperendemic in those regions. These include LHD, lung disease \& TB, rheumatic heart disease, HIV and schistosomiasis. The intersection of communicable and non-communicable diseases in SSA with, generally, late presenting patients of the two entities contributing to a broad range of $\mathrm{PH}$ in the region. Pathways leading to $\mathrm{PH}$ need to be identified early and managed accordingly. Treatment options are limited often to heart failure management. More comprehensive data on the epidemiology of PH from LMICs is desperately needed to plan for health interventions and the previously described algorithm to diagnose $\mathrm{PH}$ in LMICs needs to be validated as a screening tool for $\mathrm{PH}$. 


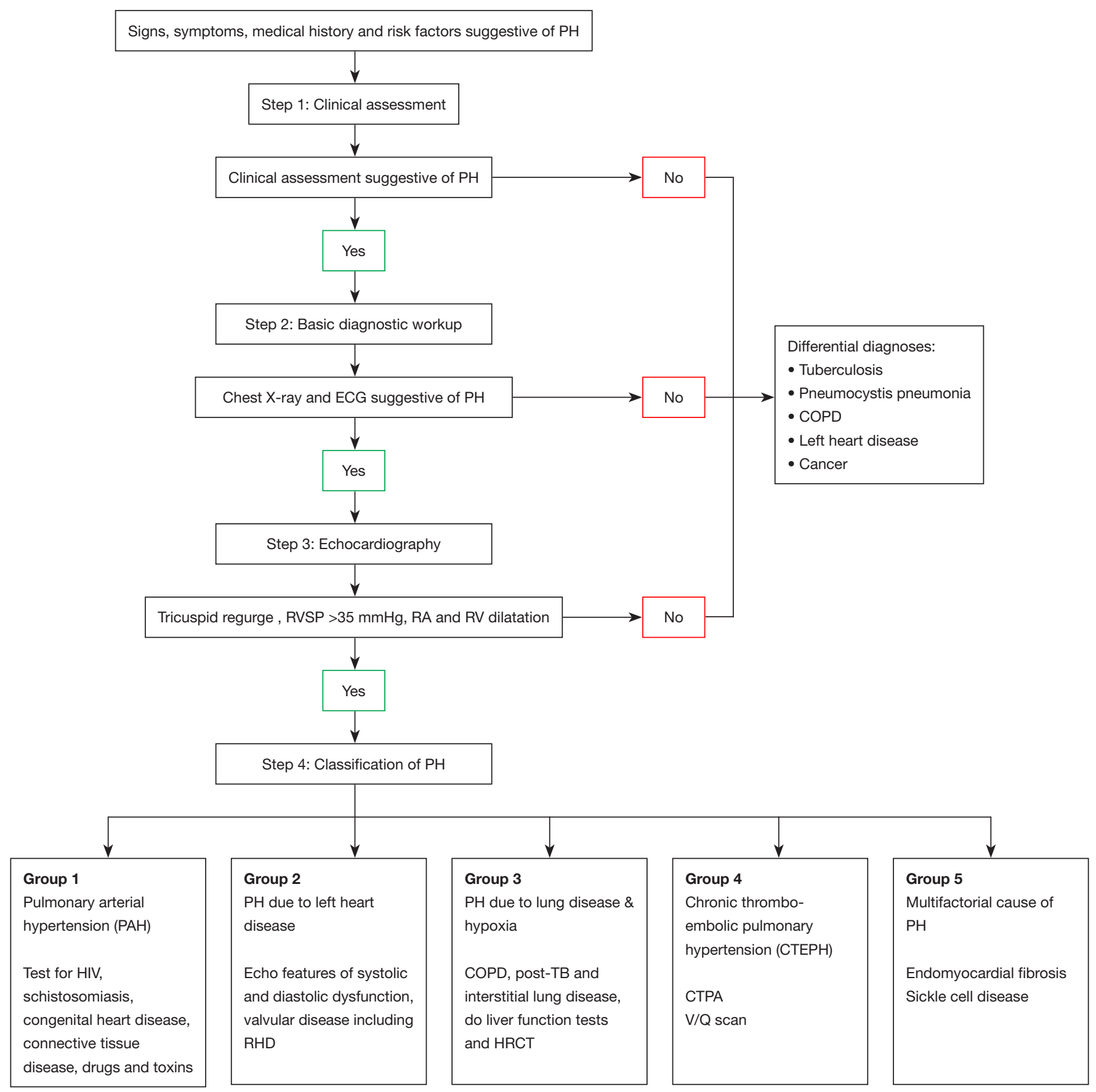

Figure 4 Proposed diagnostic algorithm for the diagnosis of PH-LHD in low-resource settings. PH, pulmonary hypertension; ECG, electrocardiography; TB, tuberculosis; PCP, pneumocystis pneumonia; COPD, chronic obstructive pulmonary disease; LHD, left heart disease; doppler echo, doppler echocardiography; HIV, human immunodeficiency virus; US, ultrasound; LFT, liver function tests; HRCT, high-resolution computerized tomography; CTEPH, chronic thromboembolic pulmonary hypertension; CTPA, CT pulmonary angiography; V/Q, ventilation/perfusion lung scan. 


\section{Acknowledgments}

Funding: None.

\section{Footnote}

Provenance and Peer Review: This article was commissioned by the Guest Editor (Ntobeko A. B. Ntusi) for the series "Cardiovascular Diseases in Low-and Middle-Income Countries" published in Cardiovascular Diagnosis and Therapy. The article was sent for external peer review organized by the Guest Editor and the editorial office.

Conflicts of Interest: The series "Cardiovascular Diseases in Low- and Middle-Income Countries" was commissioned by the editorial office without any funding or sponsorship. The authors have no conflicts of interest to declare.

Ethical Statement: The authors are accountable for all aspects of the work in ensuring that questions related to the accuracy or integrity of any part of the work are appropriately investigated and resolved.

Open Access Statement: This is an Open Access article distributed in accordance with the Creative Commons Attribution-NonCommercial-NoDerivs 4.0 International License (CC BY-NC-ND 4.0), which permits the noncommercial replication and distribution of the article with the strict proviso that no changes or edits are made and the original work is properly cited (including links to both the formal publication through the relevant DOI and the license). See: https://creativecommons.org/licenses/by-nc-nd/4.0/.

\section{References}

1. Galiè N, Humbert M, Vachiery JL, et al. 2015 ESC/ ERS Guidelines for the diagnosis and treatment of pulmonary hypertension: the joint task force for the diagnosis and treatment of pulmonary hypertension of the European Society of Cardiology (ESC) and the European Respiratory Society (ERS): endorsed by: Association for European Paediatric and Congenital Cardiology (AEPC), International Society for Heart and Lung Transplantation (ISHLT). Eur Respir J 2015;46:903-75.

2. Hoeper MM, Bogaard HJ, Condliffe R, et al. Definitions and diagnosis of pulmonary hypertension. J Am Coll Cardiol 2013;62:D42-50.

3. Thienemann F, Dzudie A, Mocumbi AO, et al. The causes, treatment, and outcome of pulmonary hypertension in Africa: insights from the pan African pulmonary hypertension cohort (PAPUCO) Registry. Int J Cardiol 2016;221:205-11.

4. Simonneau G, Montani D, Celermajer DS, et al. Haemodynamic definitions and updated clinical classification of pulmonary hypertension. Eur Respir J 2019;53. doi: 10.1183/13993003.01913-2018.

5. Simonneau G, Gatzoulis MA, Adatia I, et al. Updated clinical classification of pulmonary hypertension. J Am Coll Cardiol 2013;62:D34-41.

6. Mocumbi AO, Thienemann F, Sliwa K. A global perspective on the epidemiology of pulmonary hypertension. Can J Cardiol 2015;31:375-81.

7. Hoeper MM, Humbert M, Souza R, et al. A global view of pulmonary hypertension. Lancet Respir Med 2016;4:306-22.

8. Dzudie A, Dzekem BS, Tchoumi CT, et al. Pulmonary hypertension as seen in a rural area in sub-Saharan Africa: high prevalence, late clinical presentation and a high shortterm mortality rate during follow up. Cardiovasc J Afr 2018;29:208-12.

9. Bigna JJ, Noubiap JJ, Nansseu JR, et al. Prevalence and etiologies of pulmonary hypertension in Africa: a systematic review and meta-analysis. BMC Pulm Med 2017;17:183.

10. Strange G, Playford D, Stewart S, et al. Pulmonary hypertension: prevalence and mortality in the Armadale echocardiography cohort. Heart 2012;98:1805-11.

11. Tueller C, Stricker H, Soccal P, et al. Epidemiology of pulmonary hypertension: new data from the Swiss registry. Swiss Med Wkly 2008;138:379-84.

12. Dzudie A, Kengne AP, Thienemann F, et al. Predictors of hospitalisations for heart failure and mortality in patients with pulmonary hypertension associated with left heart disease: a systematic review. BMJ Open 2014;4:e004843.

13. Mocumbi AO, Lameira E, Yaksh A, et al. Challenges on the management of congenital heart disease in developing countries. Int J Cardiol 2011;148:285-8.

14. Brown LM, Chen H, Halpern S, et al. Delay in recognition of pulmonary arterial hypertension: factors identified from the REVEAL Registry. Chest 2011;140:19-26.

15. Hoeper MM, Madani MM, Nakanishi N, et al. Chronic thromboembolic pulmonary hypertension. Lancet Respir Med 2014;2:573-82.

16. Humbert M, Lau EM, Montani D, et al. Advances in 
therapeutic interventions for patients with pulmonary arterial hypertension. Circulation 2014;130:2189-208.

17. Thienemann F, Dzudie A, Mocumbi AO, et al. Rationale and design of the pan African pulmonary hypertension cohort (PAPUCO) study: implementing a contemporary registry on pulmonary hypertension in Africa. BMJ Open 2014;4:e005950.

18. Satoh T. Current practice for pulmonary hypertension. Chin Med J (Engl) 2014;127:3491-5.

19. Halbert RJ, Natoli JL, Gano A, et al. Global burden of COPD: systematic review and meta-analysis. Eur Respir J 2006;28:523-32.

20. D'Alonzo GE, Barst RJ, Ayres SM, et al. Survival in patients with primary pulmonary hypertension. Results from a national prospective registry. Ann Intern Med 1991;115:343-9.

21. Benza RL, Miller DP, Barst RJ, et al. An evaluation of long-term survival from time of diagnosis in pulmonary arterial hypertension from the REVEAL Registry. Chest 2012;142:448-56.

22. Karaye KM, Saidu H, Bala MS, et al. Prevalence, clinical characteristics and outcome of pulmonary hypertension among admitted heart failure patients. Ann Afr Med 2013;12:197-204.

23. Shah SJ. Pulmonary hypertension. JAMA 2012;308:1366-74.

24. Adir Y, Amir O. Pulmonary hypertension associated with left heart disease. Semin Respir Crit Care Med 2013;34:665-80.

25. Faqih SA, Noto-Kadou-Kaza B, Abouamrane LM, et al. Pulmonary hypertension: prevalence and risk factors. Int J Cardiol Heart Vasc 2016;11:87-9.

26. Ondze Kafata LI, Ngolet L, Letomo KN, et al. 0422: Echocardiographic aspects of Congolese sickle cell disease heart. Arch Cardiovasc Dis Suppl 2016;8:43.

27. Damasceno A, Mayosi BM, Sani M, et al. The causes, treatment, and outcome of acute heart failure in 1006 Africans from 9 countries. Arch Intern Med 2012;172:1386-94.

28. Soliman M, Heshmat H, Amen Y, et al. Detection of right sided heart changes and pulmonary hypertension in COPD patients. Egypt J Chest Dis Tuberc 2015;64:335-41.

29. Gaber K, Elfaitouri O, Hassi S, et al. Prevalence of Pulmonary Hypertension in Patients Attending Echocardiolgy Clinic in the Eastern Part of Libya. Chest 2014;145:516A.

30. Ahmed AE, Ibrahim AS, Elshafie SM. Pulmonary hypertension in patients with treated pulmonary tuberculosis: analysis of 14 consecutive cases. Clin Med Insights Circ Respir Pulm Med 2011;5:1-5.

31. Steenekamp JH, Simson IW, Theron W. Cardiovascular causes of death at Tshepong Hospital in 1 year, 19891990. A necropsy study. S Afr Med J 1992;81:142-6.

32. Al-Naamani N, Espitia HG, Velazquez-Moreno H, et al. Chronic Thromboembolic Pulmonary Hypertension: Experience from a Single Center in Mexico. Lung 2016;194:315-23.

33. Aminde LN, Dzudie A, Kengne AP, et al. Gender disparities in pulmonary hypertension at a tertiary centre in Cameroon. S Afr Med J 2017;107:892-9.

34. Graham BB, Bandeira AP, Morrell NW, et al. Schistosomiasis-associated pulmonary hypertension: pulmonary vascular disease: the global perspective. Chest 2010;137:20S-29S.

35. Papamatheakis DG, Mocumbi AO, Kim NH, et al. Schistosomiasis-associated pulmonary hypertension. Pulm Circ 2014;4:596-611.

36. Sokunbi OJ, Ekure EN, Temiye EO, et al. Pulmonary hypertension among 5 to 18 -year-old children with sickle cell anaemia in Nigeria. PLoS One 2017;12:e0184287.

37. Amadi VN, Balogun MO, Akinola NO, et al. Pulmonary hypertension in Nigerian adults with sickle cell anemia. Vasc Health Risk Manag 2017;13:153-60.

38. Aliyu ZY, Kato GJ, Taylor J 6th, et al. Sickle cell disease and pulmonary hypertension in Africa: a global perspective and review of epidemiology, pathophysiology, and management. Am J Hematol 2008;83:63-70.

39. Naing P, Kuppusamy H, Scalia G, et al. Non-invasive assessment of pulmonary vascular resistance in pulmonary hypertension: current knowledge and future direction. Heart Lung Circ 2017;26:323-30.

40. Dzudie A, Kengne AP, Lamont K, et al. A diagnostic algorithm for pulmonary hypertension due to left heart disease in resource-limited settings: can busy clinicians adopt a simple, practical approach? Cardiovasc J Afr 2019;30:61-7.

41. Gidwani S, Nair A. The burden of pulmonary hypertension in resource-limited settings. Glob Heart 2014;9:297-310.

Cite this article as: Dzudie A, Dzekem BS, Ojji DB, Kengne AP, Mocumbi AO, Sliwa K, Thienemann F. Pulmonary hypertension in low- and middle-income countries with focus on sub-Saharan Africa. Cardiovasc Diagn Ther 2020;10(2):316324. doi: $10.21037 / \mathrm{cdt} .2019 .07 .06$ 